УДК 621.039 .73

\title{
Methods of Decontamination of Surfaces Contamination
}

\author{
Tatyana A. Kulagina*a and Veronika V. Shelenkova ${ }^{a, b}$ \\ ${ }^{a}$ Siberian Federal University \\ 79 Svobodny, Krasnoyarsk, 660041, Russia \\ ${ }^{b}$ Mining and Chemical Combine \\ 53 Lenin Str., Zheleznogorsk, 662972, Russia
}

Received 24.11.2016, received in revised form 17.12.2016, accepted 29.01.2017

In the present review are analyzed the available data on various ways of decontamination of surfaces contamination. Special attention is paid to physical and chemical bases of process of a surface contamination and decontamination. The major factors defining the choice of a method of decontamination depending on character of a surface contamination are considered. The numerical data illustrating effectiveness of various ways of deactivation are submitted.

Keywords: decontamination, surface contamination, decontamination solution, mechanical operation, ultrasound, decontamination factor.

Citation: Kulagina T.A., Shelenkova V.V. Methods of decontamination of surfaces contaminations, J. Sib. Fed. Univ. Eng. technol., 2017, 10(3), 352-363. DOI: 10.17516/1999-494X-2017-10-3-352-363.

\section{Способы дезактивации поверхностей}

\section{с радиоактивным загрязнением}

\author{
Т.А. Кулагина ${ }^{\mathrm{a}}$, В.В. Шеленкова ${ }^{\mathrm{a}, \overline{0}}$ \\ ${ }^{a}$ Сибирский федеральный университет \\ Россия, 660041, Красноярск, пр. Свободныий, 79 \\ ${ }^{6}$ Горно-химический комбинат \\ Россия, 662972, Железногорск, ул. Ленина, 53
}

В настоящем обзоре проанализированы имеющиеся данные о различных способах дезактивачии поверхностей с радиоактивным загрязнением. Особое внимание уделено физикохимическим основам проиесса радиоактивного загрязнения и дезактивации. Рассмотрены основные факторы, определяющие выбор способа дезактивации в зависимости от характера радиоактивного загрязнения. Представлены численные данные, иллюстрирующие эффективность различных способов дезактивачии.

(c) Siberian Federal University. All rights reserved

* Corresponding author E-mail address: tak.sfu@gmail.com 
Ключевые слова: дезактивация, радиоактивное загрязнение, дезактивирующий раствор, механическая обработка, ультразвук, коэффициент дезактивации.

При эксплуатации атомных электростанций, исследовательских реакторов, кораблей и судов с ядерными транспортными установками, предприятий ядерного топливного цикла, при добыче и переработке природных ископаемых (нефти, газа, цветных металлов), а также при переработке радиоактивных отходов и отработавшего ядерного топлива происходит загрязнение оборудования, помещений и средств индивидуальной защиты персонала радиоактивными изотопами в различной химической форме и агрегатном состоянии.

Радиоактивные загрязнения классифицируют на первичные, вторичные и многократные [1]. Первичные загрязнения вызваны радиоактивными веществами, которые образовались в процессе аварии, производственной деятельности, взрывов ядерных боеприпасов. Вторичные радиоактивные загрязнения определяются переходом радиоактивности с загрязненных объектов на чистые.

Один и тот же объект может за счет вторичных процессов загрязняться несколько раз. В этих условиях вторичные загрязнения становятся многократными. Наиболее опасный источник загрязнения - выбросы радиоактивных веществ в атмосферу и распространение этих выбросов в виде аэрозольного облака. Помимо аэрозольного возможно контактное радиоактивное загрязнение, которое происходит в результате соприкосновения поверхностей различных объектов с жидкой или твердой средой, содержащей радионуклиды.

В результате деятельности топливно-энергетического комплекса (нефтегазодобывающие предприятия) и предприятий атомной промышленности возникает радиоактивное загрязнение, в том числе поверхностное. Источником радиоактивного загрязнения при добыче нефти/ газа являются природные радионуклиды Ra-226, Th-232 и продукты их распада. В атомной отрасли радиоактивное загрязнение - результат эксплуатации ядерных установок, обращения с отработанным ядерным топливом и радиоактивными отходами, и в основном обусловлено такими радионуклидами, как: изотопы урана, изотопы плутония, $\mathrm{Cs}^{137}, \mathrm{Sr}^{90}, \mathrm{Co}^{60}$.

Характер поверхностного радиоактивного загрязнения определяется следующими факторами:

1) природой поверхности;

2) радиоактивной средой, контактирующей с поверхностью;

3) состоянием поверхности и качеством ее обработки;

4) химическими свойствами и состоянием радионуклидов;

5) концентрацией радиоактивного вещества;

6) физико-химическими условиями контакта.

Радиоактивное загрязнение удерживается на поверхности материалов в результате действия сил адгезии и различных процессов сорбции: физической адсорбции, ионного обмена или других видов химсорбции, а также абсорбции. Естественно, что вклад тех или иных процессов, ответственных за фиксацию радиоактивных загрязнений, определяется как природой материала и состоянием его поверхности, так и видом загрязнений.

Следует отметить, что поверхностное радиоактивное загрязнение является значимым фактором радиационного воздействия на персонал при проведении работ с использованием 
открытых источников ионизирующего излучения. Поэтому для исключения дополнительных источников облучения персонала, образования радиоактивных аэрозолей и разноса радиоактивных загрязнений необходимо своевременно проводить дезактивацию оборудования, средств индивидуальной защиты и других загрязненных радиоактивными веществами поверхностей.

Дезактивация оборудования способствует значительному уменьшению вероятности поступления радиоактивных веществ в организм человека через органы дыхания, желудочнокишечный тракт и кожные покровы, а также снижает дозовые нагрузки персонала, занятого в условиях воздействия источников ионизирующего излучения. Образованию радиоактивных загрязнений и дезактивации его посвящено большое количество работ [120].

Таким образом, дезактивация выступает обязательным условием обеспечения радиационной безопасности. Своевременная и эффективная дезактивация имеет большое экономическое значение, так как позволяет повысить производительность труда и значительно уменьшить объем необходимых демонтажных работ, количество материалов и оборудования, направляемых на захоронение в качестве радиоактивных отходов.

Реализация любого способа дезактивации осуществляется в две стадии. Первая стадия процесса дезактивации заключается в преодолении связи между радиоактивным веществом (молекулы, ионы, радиоактивные частицы) и поверхностью обрабатываемого объекта. Вторая стадия включает транспортировку радиоактивного вещества с обрабатываемой поверхности загрязненного объекта. Если вторая стадия осуществляется не в полной мере, то происходит оседание радиоактивных веществ из отработанной среды обратно на поверхность и повторное загрязнение поверхности уже в процессе дезактивации. В случае глубинного загрязнения дезактивация заключается не только в преодолении связи между носителями радиоактивных загрязнений и поверхностью, но и в миграции этих загрязнений из глубины материала на поверхность и в последующем удалении их с поверхности.

Разграничение всего процесса дезактивации на две стадии дает возможность обосновать параметры, характеризующие конкретный способ дезактивации. К таким параметрам относятся: состав дезактивирующих растворов, норма их расхода на единицу поверхности, условия применения дезактивирующих сред (скорость обработки, давление и др.) [2].

Вследствие того, что загрязнения бывают различными по природе радиоактивных изотопов, виду их соединений и уровню создаваемой ими активности, а также вследствие разнообразия поверхностей, как правило, не удается найти универсальные для всех случаев методы дезактивации.

В основу классификации способов дезактивации можно положить два основных принципа, определяющих агрегатное состояние дезактивирующей среды и особенности проведения процесса [3].

В зависимости от состояния среды:

- жидкостные;

- безжидкостные;

- комбинированные (например, дезактивация перегретым паром безжидкостная, но после конденсации пара идет обработка жидкостью).

В зависимости от характера протекания процесса дезактивации:

$$
-354-
$$


- физико-механические - удаление радиоактивного загрязнения осуществляется с помощью механических или физических процессов без применения химических реагентов за исключением воды;

- химические - жидкостные способы, в которых основным средством воздействия является раствор химических реагентов;

- физико-химические - способы, сочетающие в себе химические, физические и механические процессы.

В соответствии с принципами классификации можно выделить следующие основные способы дезактивации:

химические

использование, дезактивирующих растворов, пенная дезактивация,

дезактивация сорбентами,

дезактивация $\mathrm{CO}_{2}$ и $\mathrm{H}_{2} \mathrm{O}$ в сверхкритическом состоянии; физико-механические вакуумирование,

механическая обработка, дезактивация ультразвуком,

термический способ,

обдув потоком газа, абразивный обдув, водоструйная и пароструйная дезактивация; физико-химические электрохимическая дезактивация,

дезактивация пастами, суспензиями, расплавами, дезактивация съемными покрытиями, струйный способ с раствором химических реагентов, паровая дезактивация с использованием химических реагентов,

дезактивация порошкообразными металлизированными составами.

Рассмотрим некоторые из предлагаемых способов дезактивации.

В группе химических методов средством воздействия на загрязненную поверхность является дезактивирующий раствор или другая среда, содержащая химические реагенты.

Использование дезактивирующих растворов относится к жидкостным методам дезактивации. Процесс дезактивации поверхностей материалов в этом случае можно выразить следующим образом [1]:

\section{(поверхность + загрязняющее вещество) + моющий раствор $\rightarrow$ \\ $\rightarrow$ поверхность + (моющий раствор + загрязняющее вещество).}

Поверхность освобождается от радиоактивного загрязнения, а радиоактивное вещество переходит в моющий раствор, т.е. происходит разрушение связи загрязнения с поверхностью. При этом состав моющего раствора подбирают таким образом, чтобы наиболее эффективно разрушить связь радиоактивных изотопов с поверхностью и предотвратить их повторную сорбцию, т.е. приведенный выше процесс должен быть направлен только слева направо.

Основные компоненты дезактивирующих растворов - вода, поверхностно-активные и комплексообразующие вещества, кислоты, щелочи, окислители и некоторые соли. В большинстве случаев применяют сложные растворы, состав которых выбирают с учетом сил, удерживающих загрязняющее вещество на поверхности. Хороший эффект часто дает поочередное использование различных растворов, например кислого и щелочного, окислительного и восстановительного [4].

В качестве добавки, улучшающей удержание радиоактивных загрязнений в растворе, берут карбоксилметилцеллюлозу, которая образует коллоидный раствор. В табл. 1 представле- 
ны экспериментально полученные коэффициенты дезактивации загрязненных стальных поверхностей методом орошения разными растворами при одновременной обработке щеткой (60 об/мин) [1].

Растворы различного состава использовались при одной и той же норме расхода, равной 3 л/м². Применение меньшей нормы расхода, например 1 л/м², из-за неровностей обрабатываемой поверхности может привести к неполному ее смачиванию, что снизит качество дезактивации. Поэтому обычно норма расхода дезактивирующего раствора составляет $2-3$ л/м².

Эффективность проведения дезактивации в зависимости от времени обработки представлена в табл. 2 [1]. В этих экспериментах для дезактивации поверхности, загрязненной радионуклидами ${ }^{89} \mathrm{Sr}$ и ${ }^{91} \mathrm{Y}$, использовался $0,1 \%$-й раствор препарата СФ-2 при норме расхода 3 л/м ${ }^{2}$ при одновременном воздействии щетки (60 об/мин).

Из табл. 2 следует, что при увеличении в 8 раз времени обработки поверхности, загрязненной ${ }^{89} \mathrm{Sr}$, коэффициент дезактивации увеличивается всего на 30 \%, что указывает на нерациональный расход дезактивирующих растворов и неэффективность затраченного на обработку времени [5].

Препараты, которые маркируются шифром СФ, предназначены для дезактивации техники, одежды и других объектов. Такие препараты поступают к потребителю в виде порошка, из которого готовятся $0,1-0,5 \%$-е водные дезактивирующие растворы. Состав препаратов СФ представлен в табл. 3 .

Примером использования дезактивирующих растворов служат способы погружной дезактивации и дезактивации растиранием раствора. Эффективность погружной дезактивации возрастает при перемешивании, циркуляции раствора, повышении температуры. Метод подходит для дезактивации съемного контурного оборудования, оснастки, арматуры, инструментов. При дезактивации крупногабаритного оборудования (парогенераторов, теплообменников, больших емкостей) их заполняют дезактивирующим раствором, организуя его циркуляцию и

Таблица 1. Коэффициенты дезактивации стальной поверхности, полученные методом орошения разными растворами при одновременной обработке щеткой

\begin{tabular}{|l|c|}
\hline \multicolumn{1}{|c|}{ Состав раствора } & $K_{\text {д }}$ \\
\hline Чистая вода & 2,5 \\
\hline $0,1 \%$ Гексаметафосфат натрия (ГМФН) & 8,7 \\
\hline $0,1 \%$ Карбоксилметилцеллюлоза (КМЦ) & 13,6 \\
\hline $0,1 \%$ Препарат СФ-2 & 13,7 \\
\hline $0,1 \%$ ГМФН + 0,1 \% (КМЦ) & 14,1 \\
\hline
\end{tabular}

Таблица 2. Коэффициент дезактивации поверхности 0,1\%-м раствором СФ-2

\begin{tabular}{|c|c|c|c|c|}
\hline \multirow{2}{*}{$\begin{array}{c}\text { Загрязняющий } \\
\text { радионуклид }\end{array}$} & \multicolumn{4}{|c|}{ Время обработки, с } \\
\hline & 2,7 & 5,5 & 16,5 & 22,5 \\
\hline $\mathrm{Sr}^{89}$ & 22 & 23 & 27 & 29 \\
\hline $\mathrm{Y}^{91}$ & 29 & 30 & 37 & 40 \\
\hline
\end{tabular}


подогрев. Недостаток - большой расход дезактивирующего раствора и, как следствие, большой объем ЖРО [3].

Дезактивация растиранием раствора осуществляется дезактивирующим действием раствора в сочетании с механическим воздействием щетки или ветоши - простой, универсальный и распространенный способ. Используются растворы кислот, щелочей, и более сложные рецептуры. Согласно [4], расход раствора составляет 23 л/ $\mathrm{M}^{2}$. Для нержавеющей стали коэффициент дезактивации равен 5-20.

Достоинства - возможность проводить обработку оборудования сложной формы и труднодоступных участков. Недостаток - применение ручного труда в радиационно-опасных условиях, как следствие дозовые нагрузки на персонал.

Эффективность дезактивации химическими растворами можно увеличить интенсификацией процесса, например приложением разности потенциалов.

Установлено, что при этом процесс удаления радиоактивных веществ с поверхности металла ускоряется в несколько раз [6]; кроме того, частичному растворению подвергается и сам металл, что обеспечивает удаление глубоко продиффундировавших радиоактивных загрязнений. Тем не менее наличие или образование в процессе электролиза на поверхности металла труднорастворимых оксидных пленок замедляет анодное растворение металлов, вплоть до его полного прекращения (явление пассивации), и снижает эффективность дезактивации.

Группой авторов во главе с А.А. Акатовым, Ю.С. Коряковским были проведены эксперименты с использованием натурных радиоактивно загрязненных образцов нержавеющей стали. Результаты эксперимента представлены на рис. 1.

Основной измеряемой величиной являлся коэффициент дезактивации. Обработка проводилась в течение 20 мин при комнатной температуре. Низкий уровень загрязнения предоставленных образцов определил невысокие коэффициенты дезактивации: в случае совместной ультразвуковой и электрохимической обработки за 20 мин практически удалось достигнуть фоновых значений [7].

Таблица 3. Состав препаратов типа СФ, применяемых для приготовления дезактивирующих растворов [1]

\begin{tabular}{|c|c|c|c|c|c|}
\hline \multicolumn{2}{|c|}{ Компоненты } & \multicolumn{4}{|c|}{ Содержание, масс. \% } \\
\hline назначение & название & СФ-2 & СФ-2У & СФ-3 & СФ-3К \\
\hline \multirow{2}{*}{ ПАВ } & Алкилбензолсульфонаты & 25 & 18 & $18-20$ & 9 \\
\hline & Триполифосфат натрия & - & 50 & - & 25 \\
\hline \multirow{2}{*}{ Комплексообразователи } & Гексаметафосфат натрия & - & - & 25 & - \\
\hline & Тринатрийфосфат & 30 & - & - & - \\
\hline Кислый реагент & Щавелевая кислота & - & - & - & 50 \\
\hline \multicolumn{6}{|c|}{ Активные добавки } \\
\hline $\begin{array}{l}\text { Для улучшения качества } \\
\text { обрабатываемых изделий }\end{array}$ & $\begin{array}{l}\text { Органический } \\
\text { отбеливатель }\end{array}$ & - & - & 2 & 1 \\
\hline Примеси & $\begin{array}{c}\text { Несульфированные } \\
\text { вещества и вода }\end{array}$ & Остальное & Остальное & Остальное & Остальное \\
\hline
\end{tabular}




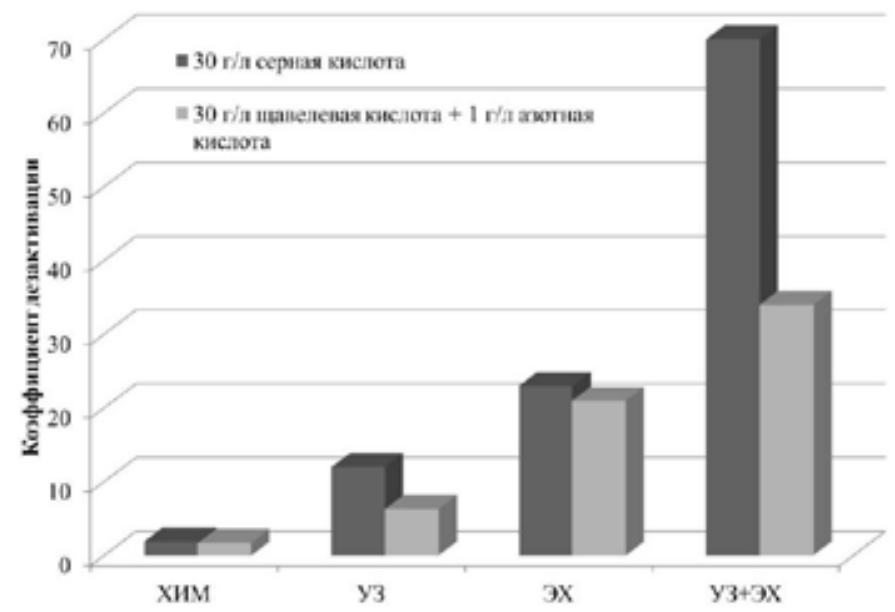

Рис. 1. Результаты обработки натурных радиоактивно загрязненных (цезий-137) образцов нержавеющей стали $[7,18]$

Помимо химических методов дезактивации также можно выделить группу физикомеханических методов.

Способы механической обработки используются для пористых и непористых материалов (дерево, бетон, металлы). В ходе механической обработки удаляется поверхностный слой материала с содержащимися в нем радиоактивными загрязнениями. К механическим методам обработки относят шлифование, фрезерование, бурение и разламывание, дезактивацию отбойным молотком или зубилом [3].

Для интенсификации процесса дезактивации может быть использован ультразвук. Ультразвуковая обработка активно применяется для ускорения химической дезактивации металлических РАО $[8,14,18]$, позволяя достичь достаточно высокой эффективности обработки за сравнительно короткое время, благодаря чему снижаются объемы вторичных жидких РАО. Однако прочнофиксированные загрязнения, особенно продиффундировавшие вглубь основного металла, ультразвуком удаляются плохо - даже с помощью агрессивных растворов [7].

Эффективность дезактивации нержавеющей стали растворами при наложении ультразвуковых колебаний можно сравнить с эффективностью обработки обычными способами, что демонстрируется данными, приведенными в табл. 4 [1]. Из таблицы следует, что при наложении

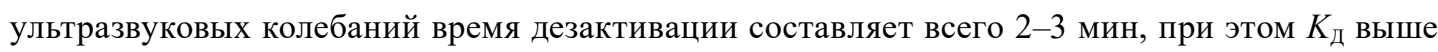
в 7-20 раз.

К недостатку ультразвуковой дезактивации следует отнести громоздкое и энергоемкое оборудование для генерирования ультразвуковых волн. Из-за этого ультразвуковые ванны применяют для сравнительно небольших деталей. Метод принципиально не может быть применен для бетона и прочих материалов, поглощающих ультразвуковые колебания.

Среди физико-механических способов наиболее широко распростронен способ дезактивации струей воды. При реализации данного способа струя воды под давлением воздействует на поверхность. Удаление радиоактивного загрязнения достигается за счет кинетической энергии 
струи. На рис. 2 изображена ванна струйного типа, предназначенная для деталей сложной конфигурации.

Эффективность дезактивации зависит от энергии удара струи, т.е. от ее скорости и давления. Для эффекта скалывающего действия нужна высокая скорость струи - 2025 м/с, температура повышенная, $\sim 8{ }^{\circ} \mathrm{C}$ (температура воды существенной роли не играет). Давление и скорость потока выбираются исходя из конкретной ситуации. В зависимости от давления струя воды позволяет удалить со стали краску, покрытия (в т.ч. нанесенные гальванически) и прочнофиксированные загрязнения без повреждения внутреннего слоя металла. Струя воды может быть сплошной или разделенной на отдельные компактные струйки, а также может быть и капельного строения. Поэтому первую стадию процесса дезактивации рассматривают с трех позиций: воздействие сплошной водной струи, струи капельного строения и пленки воды, образовавшейся после контакта струи с поверхностью. Для определения зависимости между временем дезактивации и расходом воды можно взять экспериментальные данные, полученные для коэффициента дезактивации при использовании сплошной струи и струи капельного строения при различном времени обработки поверхности (табл. 5) [1].

Повысить интенсивность дезактивации струей воды можно путем перехода на импульсную обработку, которая заключается в чередовании включения и выключения источника, генерирующего струю воды. При этом каждый раз, когда включается источник, струя воды падает на поверхность, где нет водной пленки.

Также для увеличения эффективности дезактивации применяют смесь воды с водяным паром (пароэмульсионную смесь) или чистый водяной пар. Струя пара действует на радиоактив-

Таблица 4. Эффективность дезактивации поверхности нержавеющей стали различными способами

\begin{tabular}{|l|c|c|}
\hline \multicolumn{1}{|c|}{ Способ обработки } & Время обработки, мин & $K_{\text {д }}$ \\
\hline Протирка вручную & $60-90$ & 10,0 \\
\hline Окунание и перемешивание & $10-15$ & 3,3 \\
\hline Струей воды & $10-20$ & 6,6 \\
\hline При наложении ультразвуковых колебаний & $2-3$ & 67 \\
\hline
\end{tabular}

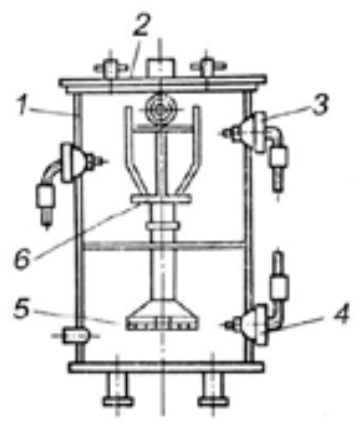

Рис. 2. Дезактивационная ванна струйного типа [3]: 1 - корпус, 2 - крышка, 3 - поворотные сопла, 4 - сопло системы привода турбины, 5 - турбина, 6 - поворотный стол с корзиной 
Таблица 5. Зависимость коэффициента дезактивации замасленных загрязненных радионуклидами поверхностей от удельного расхода воды

\begin{tabular}{|c|c|c|c|}
\hline Строение струи & $\begin{array}{c}\text { Время } \\
\text { обработки, с }\end{array}$ & $\begin{array}{c}\text { Суммарный расход } \\
\text { воды, л/м² }\end{array}$ & $\begin{array}{c}\mathrm{K}_{\text {д для частиц }} \\
\text { 5-100 мк }\end{array}$ \\
\hline \multirow{3}{*}{ Сплошная струя } & 1,0 & 7,5 & 6 \\
\hline & 2,0 & 15,0 & 17 \\
\hline & 3,0 & 30,0 & 19 \\
\hline \multirow{4}{*}{$\begin{array}{l}\text { Струя капельного } \\
\text { строения }\end{array}$} & 2,5 & 1,8 & 3 \\
\hline & 5,0 & 3,5 & 6 \\
\hline & 10,0 & 7,0 & 20 \\
\hline & 15,0 & 10,5 & 25 \\
\hline
\end{tabular}

ное загрязнение подобно воздушной струе, создавая аэродинамическую силу отрыва радиоактивных частиц от поверхности. В отличие от струи воздуха, которая бессильна в отношении глубинных радиоактивных загрязнений, дезактивация паром способна удалять адгезионные загрязнения, находящиеся в порах и выемах, а также часть адсорбированных радионуклидов.

Может использоваться как перегретый пар, который не конденсируется на обрабатываемой поверхности, так и пар, конденсирующийся при соприкосновении с поверхностью. Струя пара обладает большой кинетической энергией и, следовательно, большей возможностью по удалению радиоактивных загрязнений, что и определяет эффективную обработку паром, когда коэффициент дезактивации может достигать 200-300 [9].

Из приведенных выше способов дезактивации в настоящее время чаще всего применяется химическая дезактивация, основанная на обработке защитных покрытий дезактивирующими растворами. Представленные численные данные значений коэффициентов дезактивации показывают, что эффективность дезактивации химическими растворами увеличивается при интенсификации процесса, например, ультразвуковой обработкой или приложением разности потенциалов. Использование дезактивирующих растворов в сочетании с механическим воздействием также увеличивает коэффициент дезактивации.

В работах авторов [21-30] представлены результаты исследований в данной области, а также в направлении обращения с особо опасными отходами переработки отходов ядерного топлива, связанными с выводом атомных объектов из эксплуатации и подготовке к длительному хранению и захоронению жидких радиоактивных отходов.

Стоит отметить, что при выборе метода дезактивации необходимо также учитывать количество образующихся жидких радиоактивных отходов, дозовые нагрузки персонала, а также экономические показатели.

\section{Список литературы}

[1] Зимон А.Д., Пикалов В.К. Дезактивачия. М.: Атомиздат, 1994. 336 c. [Zimon A.D., Pikalov V.K. Decontamination. М.: Atomizdat, 1994. 336 p. (in Russian)]

[2] Лекции Теплых В.Ф. [Teplyh V.F. Lectures] http://www.chemanalytica.com/book/novyyspravochnik-khimika-i-technologa 
[3] Коряковский Ю.С., Акатов А.А., Доильницын В.А. Дезактиваџия: обеспечение радиаиионной безопасности на предприятиях ядерной отрасли. СПб.: СПбГТИ(ТУ), 2010. 150 с. [Koryakovsky Y.S., Akatov A.A., Doilnitsyn V.A. Decontamination: radiation safety at the enterprises of the nuclear industry. SPb.: SPbSTI (TU), 2010. 150 p. (in Russian)]

[4] Городинский С.М., Гольдштейн Д.С. Дезактивация полимерныхх материалов. М.: Атомиздат, 1975, 224 c. [Gorodinskiy S.M., Goldstein D.S. Decontamination of polymeric materials. M.: Atomizdat, 1975. 224 p. (in Russian)].

[5] Анисимов А.И., Осминин В. Сб.: Исследования по химии и технологии и применению радиоактивных веществ. Л.: Изд. Ленинградского технологического института, 1988, 94-98. [Anisimov A.I., Osminin V. Collection: Studies on Chemistry and Technology and the use of radioactive substances. L.: Publishing. Leningrad Institute of Technology, 1988, 94-98 (in Russian)]

[6] Новый справочник химика и технолога. Радиоактивные вещества. Вредные вещества. Гигиенические нормативы. СПб.: АНО НПО «Профессионал», 2004. 1142 с. [The new directory chemist and technologist. Radioactive substances. Harmful substances. Hygienic standards. SPb .: ANO NPO "Professional", 2004, 1142 p. (in Russian)]

[7] Акатов А.А., Коряковский Ю.С., Доильницын В.А., Лебедев Н.М., Арефьева А.Н. Глубокая дезактивация металлов с применением ультразвука и электрохимических реакций. Актуальные вопросы ядерно-химических технологий и экологической безопасности: Сб. трудов научно-практической конференции, С. 57-60 [Akatov A.A., Koryakovsky Y.S., Doilnitsyn V.A., Lebedev N.M., Aref'eva A.N. Deep decontamination of metal with ultrasound and electrochemical reactions. Actual problems of nuclear and chemical technologies and ecological safety: Proceedings of the scientific-practical conference, p. 57-60 (in Russian)].

[8] Савкин А.Е., Карлина О.К., Васильев А.П. и др. Испытания ультразвуковой установки для дезактивации металлических радиоактивных отходов. Безопасность окружающей среды. 2007, 3, 38-41 [Savkin A.E., Carlin D.C., Vasiliev A.P. etc. Tests ultrasonic device for decontamination of metal radioactive waste. Safety Environment. 2007, № 3, 38-41 (in Russian)].

[9] Полуэктова Г.Б., Ковальчук О.В., Круглов А.К. Снятие АЭС с эксплуатации. Атомная техника за рубежсм, 1990, 8, 913 [Poluektova G.B., Kovalchuk O.V., Kruglov A.K. Nuclear power plant decommissioning. Atomic energy technology abroad, 1990, 8, 913 (In Russian)].

[10] Мансиев Г.Г. Дезактивация радиоактивных загрязнений. Евразийский союз ученыхх, 2015, 5-3(14), 123-125 [Munciev G.G. Decontamination of radioactive contamination. Eurasian Union of Scientists, 2015, 5-3(14), 123-125 (in Russian)].

[11] Брус И.Д., Тураев Н.С., Павлов А.Л. Дезактивация оборудования реакторных заводов путем выделения газообразных веществ в объеме коррозионных отложений. Известия высших учебных заведений. Физика, 2010, 53(11), 124-125 [Brus I.D., Turaev N.S., Pavlov A.L. Decontamination of equipment of reactor plants by allocating the amount of gaseous substances in corrosion deposits. Proceedings of the higher educational institutions. Physics, 2010, 53(11), 124-125 (in Russian)].

[12] Коряковский Ю.С., Доильницын В.А., Акатов А.А. Применение усовершенствованных пленкообразующих полимерных композиций для повышения эффективности дезактивации металлов. Актуальные вопросы ядерно-химических технологий и экологической безопасности: Сб. статей по материалам научно-практической конференции. Севастополь, 2016, 142- 
145 [Koryakovsky Y.S., Doilnitsyn V.A. Akatov A.A. The use of advanced film-forming polymer compositions for increasing the efficiency of decontamination of metals. Actual problems of nuclear and chemical technologies and ecological safety: Collected articles on materials of scientific-practical conference. Sevastopol, 2016, 142-145 (in Russian)].

[13] Шафикова С.Н., Шафиков Д.Н., Белозуб А.Н. Оценка применимости современных моющих средств для целей дезактивации. Bопросы радиационной безопасности, 2012, 2, 11-18 [Shafikova S.N. Shafikov D.N., Belozub A.N. Evaluation of the applicability of modern detergents for decontamination purposes. Radiation Safety Questions, 2012, 2, 11-18 (in Russian)].

[14] Аксенов В.И., Кадников А.А., Шастин А.Г. и др. Новые способы применения ультразвука для дезактивации оборудования ЯЭУ. Вопросы радиационной безопасности, 2012, 1, 10-15 [Aksyonov V.I., Kadnikov A.A., Shastin A.G. etc. New ways to use of ultrasound for the decontamination of equipment NPP. Radiation Safety Questions, 2012, 1, $10-15$ (in Russian)].

[15] Омельянюк М.В. Дезактивация нефтепромыслового оборудования от природных радионуклидов. Экология и промышленность России, 2013, 2, 19 [Omelyanyuk M.V. Decontamination of oilfield equipment from natural radionuclides. Ecology and Industry of Russia, 2013, 2, 19 (in Russian)].

[16] Абраменко В.И., Черников М.А. Пеногашение в технологии пенной дезактивации загрязненного оборудования. Экология и промышленность. России, 2012, 5, 12-15 [Abramenko V.I., Chernikov M.A. Defoaming technology in foam decontamination of contaminated equipment. Ecology and Industry of Russia, 2012, 5, 12-15 (in Russia)].

[17] Балонов М.И., Голиков В.Ю., Пархоменко В.И., Пономарев А.В. Дезактивация населенных пунктов Брянской области после аварии на Чернобыльской АЭС. Радиационная гигиена, 2014, 7(1), 5-15 [Balonov M.I., Golikov V.Yu., Parkhomenko V.I., Ponomarev A.V. Decontamination of settlements of the Bryansk region after the Chernobyl accident. Radiation Hygiene, 2014, 7(1), 5-15 (in Russian)].

[18] Лебедев Н.М., Арефьева А.Н., Васильев А.П., и др. Универсальный промышленные комплекс для дезактивации металлических радиоактивных отходов с использованием ультразвука и электрохимии. Инновационные проекты и технологии ядерной энергетики: Сб. трудов IV Международной научно-технической конференции. Москва, 2016. 489-494 [Lebedev N.M., Aref'eva A.N., Vasiliev A.P., etc. Universal industrial complex for decontamination of metal radioactive waste using ultrasound and Electrochemistry. Proceedings of the IV International scientific-technical conference "Innovation projects and technologies of nuclear power". Moscow, 2016. 489-494 (in Russia)].

[19] Широков С.С., Кузнецов А.Ю., Холопова О.В. Исследование процесса дезактивации металлических изделий с учетом обратной сорбции радионуклидов. Радиохимия, 2015, 2. 154156 [Shirokov S.S., Kuznetsov A.U., Kholopova O.V. Investigation of the process of decontamination of metal products, taking into account the reverse sorption of radionuclides. Radiochemistry, 2015, 2, 154-156 (in Russia)].

[20] Клочков В.Н., Рубцов В.И. Дезактивация средств индивидуальной защиты при ликвидации последствий радиационной аварии: опыт Чернобыля и его применение в современных условиях. Медицинская радиология и радиаџионная безопасность, 2016, 4, 19-23 [Klotchkov V.N., Rubtsov V.I. Decontamination of personal protective equipment at liquidation of consequences a 
radiological accident Chernobyl experience and its application in modern conditions, Nuclear Medicine and Radiation Safety, 2016, 4, 19-23 (in Russian)].

[21] Кулагина Т.А., Кулагин В.А., Матюшенко А.И. Техносферная безопасность в ядерной энергетике. Красноярск: Изд-во «Гротеск», СФУ, 2014. 286 с. [Kulagina T.A., Kulagin V.A. Matiushenko A.I. The Technosphere safety in nuclear power. Krasnoyarsk: Publishing House of the Grotesque", SFU, 2014. 286 p. (in Russian)].

[22] Кулагина Т.А., Козин О.А., Матюшенко А.И. Экологическая безопасность техносферных объектов. Красноярск: Изд-во «Гротеск», 2015. 323 с. [Kulagina T.A., Kozin O.A. Matiushenko A.I. Environmental safety technospheric objects. Krasnoyarsk: Publishing House of the «Grotesque», 2015. 323 p. (in Russian)].

[23] Гутенев В.В., Кулагина Т.А., Кулагина Л.В. и др. Экология техносферы. М.: Издво «Маджента», 2008. 468 с. [Gutenev V.V., Kulagina T.A., Kulagina L.V. et al. Ecology of the technosphere. M .: Publishing house "Magenta", 2008. 468 p. (in Russian)].

[24] Кулагин В.А., Кулагина Т.А., Матюшенко А.И. Переработка отработавшего ядерного топлива и обращение с радиоактивными отходами. J. Sib. Fed. Univ. Eng. technol., 2013, 6(2), 123149. [Kulagin V.A., Kulagina T.A., Matiushenko A.I. Recycling of spent nuclear fuel and radioactive waste management. J. Sib. Fed. Univ. Eng. technol., 2013, 6(2), 123-149 (in Russian)].

[25] Kulagina T.A., Kozin O.A. Extraction of deposits in enterprises for processing spent nuclear fuel. Chemical and Petroleum Engineering, January, 2011, 46(9), 573-584.

[26] Кулагина Т.А. Козин О.А. Разработка экоэффективных способов утилизации отходов радиохимических производств. Безопасность жизнедеятельности. 2010, 11, 31-38. [Kulagin T.A., Kozin O.A. Development eco-efficient ways of recycling waste of radiochemical productions, Life Safety, 2010, 11, 31-38. (in Russian)].

[27] Kulagina T.A., Kulagin V.A., Popkov V.A. Compounding of spent nuclear fuel, J. Sib. Fed. Univ. Eng. technol., 2016, 9(2), 280-295, DOI: 10.17516/1999-494X-2016-9-2-280-295.

[28] Kulagina T.A., Popkov V.A. Preparation of Radioactive Waste to Long Storage (Burial) Using of the Cement Compound. Journal of Siberian Federal University. Engineering \& Technologies, 2015, 8(7), 917-927. DOI: 10.17516/1999-494X-2015-8-7-917-927.

[29] Kulagina T.A., Gafarova V.V. Safe methods of radioactive waste utilization. J. Sib. Fed. Univ. Eng. technol., 2016, 9(4), 585-597. DOI: 10.17516/1999-494X-2016-9-4-585-597.

[30] Kulagina T.A., Kulagin V.A., Moskvichev V.V., Popkov V.A. The Use of Cavitation Technology in the Treatment of Spent Nuclear Fuel Processes. Ecology and Industry of Russia, 2016, 20(10), 4-10. 